
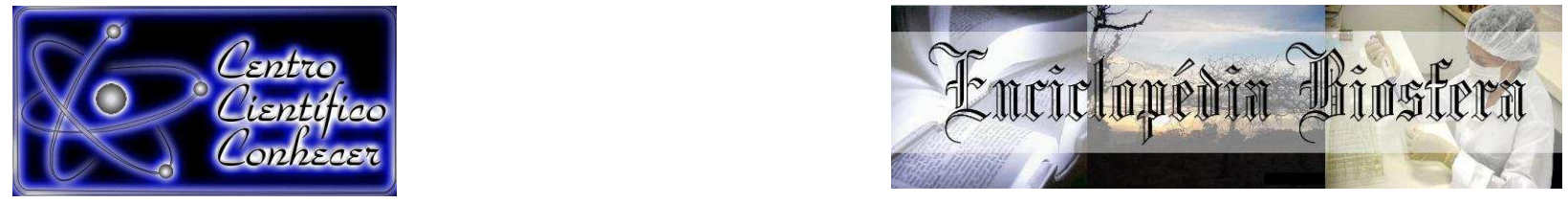

\title{
FLORÍSTICA E UTILIZAÇÃO DE ESPÉCIES FLORESTAIS EM ASSENTAMENTO AGROEXTRATIVISTA, AMAPÁ, AMAZÔNIA ORIENTAL
}

\footnotetext{
Maurício Alves Sardinha1, João da Luz Freitas², Adriano Castelo dos Santos ${ }^{3}$, Francisco de Oliveira Cruz Junior ${ }^{4}$, Erick Silva dos Santos ${ }^{5}$

${ }^{1}$ Mestre em Desenvolvimento Regional - Universidade Federal do Amapá, Macapá, Brasil. (mauricio-sardinha@bol.com.br)

2 Doutor em Ciências Agrárias - Instituto de Pesquisas Científicas e Tecnológicas do Estado do Amapá

${ }^{3}$ Mestre em Biodiversidade Tropical - Instituto Estadual de Florestas do Amapá

${ }^{4}$ Mestre em Biodiversidade Tropical - Instituto de Pesquisas Científicas e

Tecnológicas do Estado do Amapá

${ }^{5}$ Mestre em Direito ambiental e Políticas Públicas - Instituto de Pesquisas

Científicas e Tecnológicas do Estado do Amapá
}

Recebido em: 02/10/2017 - Aprovado em: 21/11/2017 - Publicado em: 05/12/2017 DOI: 10.18677/EnciBio_2017B33

\begin{abstract}
RESUMO
Em comunidades tradicionais e assentamentos rurais da Amazônia são comuns os processos de manejos com intuito de disponibilizar madeira para pequenas construções e diversos produtos florestais não madeireiros (PFNMs), como os frutos e plantas utilizadas na medicina popular. Sendo assim, objetivou-se descrever os aspectos florísticos e o potencial de utilização das espécies florestais de um fragmento de floresta ombrófila densa aluvial situada no estuário amazônico, Foz do Rio Mazagão, Estado do Amapá. Para conhecimento da estrutura florestal foram inventariadas 19 parcelas ( 3 ha de área total inventariada). Foram obtidos os dados dendrométricos como a altura total e circunferência, com nível de inclusão de circunferência à altura do peito $(C A P) \geq 30 \mathrm{~cm}$. Para avaliar o potencial de utilização madeireira, aplicou-se formulários para levantamento de informações socioeconômicas dos assentados, além da obtenção de informações na literatura existente sobre o assunto. A família com maior riqueza de espécies na amostragem total foi: Fabaceae com 17 espécies $(26,15 \%)$. Dentre as espécies mais abundantes, a Mora paraensis (Ducke) Ducke (260), Pentaclethra macroloba (Willd.) Kuntze (104), Calycophyllum spruceanum (Benth.) Hook. f. ex K. Schum. (62) contribuíram com 426 indivíduos, $48,1 \%$ da densidade total amostrada. O H' para a área total foi de 2,959 nats/indivíduo, indicando que esse ambiente florestal apresenta diversidade florística compatível com o ecossistema de várzea.
\end{abstract}

PALAVRAS - CHAVE: Etnoespécie, fitossociologia, manejo florestal. 


\title{
FLORISTIC AND USE OF FOREST SPECIES IN AGROEXTRACTIVIST SETTLEMENT, AMAPÁ, EASTERN AMAZON
}

\begin{abstract}
In traditional communities and rural settlements in the Amazon it is common to manage small wood and small non-timber forest products (NTFPs), such as fruits and plants used in popular medicine. Thus, the objective was to describe the floristic aspects and the potential of the use of forest species of an alluvial dense ombrophilous forest fragment located in the Amazonian estuary, Foz do Rio Mazagão, Amapá State. For the knowledge of the forest structure, 19 plots (3 hectares of total inventoried area) were inventoried. Dendrometric data were obtained as the total height and circumference, with inclusion level of circumference at breast height $(\mathrm{CBH}) \geq 30$ centimeters. To assess the potential for timber utilization, forms were applied to collect socioeconomic information of the settlers, besides obtaining information in the existing literature on the subject. The family with the greatest species richness in the total sampling was Fabaceae with 17 species (26.15\%). Among the most abundant species, M. paraensis (260), P. macroloba (104), C. spruceanum (62) contributed 426 individuals, $48.1 \%$ of the total density sampled. The H' for the total area was 2,959 nats/individual, indicating that this forest environment presents floristic diversity compatible with the floodplain ecosystem.
\end{abstract}

KEYWORDS: Ethnospecie, phytosociology, forest management.

\section{INTRODUÇÃO}

Nos assentamentos rurais, os lotes podem ser manejados e ofertar tanto a madeira como diversos produtos florestais não madeireiros (PFNMs), além de contribuir para mudanças no pensamento local de aproveitamento unilateral da floresta (ALMEIDA et al., 2012). Estes tipos de atividades são característicos em comunidades tradicionais e assentamentos rurais da Amazônia. No estado do Amapá, por exemplo, a comunidade do assentamento Foz do Mazagão Velho, localizada em ambiente de várzea, mantém seu modo de vida e sobrevivência, em sua maior parte diretamente ligados ao extrativismo de produtos da floresta, como frutos para alimentação, medicina popular, bem como extração da madeira para a construção de casas e embarcações (LOMBA; FONSECA, 2017).

Ressalta-se ainda, que o setor madeireiro tem papel fundamental na geração de emprego e renda para os trabalhadores da floresta e indústria, e movimenta indiretamente a economia de mais de um terço dos municípios Amazônicos. No ano de 2009, essa atividade estava presente em cerca de 71 polos de extração e processamento próximos as principais rodovias, como também na região do estuário do rio Amazonas (VERÍSSIMO; PEREIRA, 2014).

No entanto, a obtenção de renda por parte de populações extrativistas a partir do emprego dos PFNMs enfrentam alguns entraves quanto aos poucos estudos sobre as suas viabilidades diante do mercado. Um exemplo aplicável disso é o do potencial de amêndoas de Dipteryx odorata (Aubl.) Willd. (cumaru) nas cidades paraenses de Santarém e Alenquer (RÊGO et al., 2016). Nesse sentido, a fitossociologia destaca-se como um instrumento fundamental na determinação das espécies mais importantes dentro de uma comunidade específica e que podem ser destinados ao bom manejo e ao uso como geração de renda para populações locais.

A estimativa de parâmetros como diversidade, frequência, densidade, dominância e as distribuições diamétrica e espacial das espécies constitui o estudo da estrutura da floresta, baseada nas dimensões das árvores e suas distribuições, 
permitindo estimar características como estágio de desenvolvimento, qualidade e produtividade (ALMEIDA et al., 2012; CHAVES et al., 2013; SOUZA; SOARES, 2013). Desta forma, o objetivo deste trabalho foi descrever os aspectos florísticos e forma de uso das etnoespécies indicadas pelos moradores de um assentamento agroextrativista.

\section{ÁREA DE ESTUDO}

\section{MATERIAL E MÉTODOS}

O estudo foi realizado no Município de Mazagão, especificamente na Foz do Rio Mazagão (Figura 1), ao Sul do Estado do Amapá, nas coordenadas $00^{\circ} 11^{\prime}$ $17,24^{\prime \prime}$ de latitude, $51^{\circ} 21^{\prime} 11,56$ " de longitude. O clima na região é da categoria Ami, segundo a classificação de Koppen, tropical chuvoso. O período chuvoso vai de janeiro a julho com precipitação média anual de $2300 \mathrm{~mm}$, temperatura média anual de $28{ }^{\circ} \mathrm{C}$, e umidade relativa do ar de $85 \%$ (YOKOMIZO et al., 2016).

A vegetação predominante é do tipo floresta ombrófila densa aluvial, isto é, floresta de várzea de alto porte com grande frequência de palmeiras e com influência diária de marés dos rios circundantes (QUEIROZ; MACHADO, 2008).

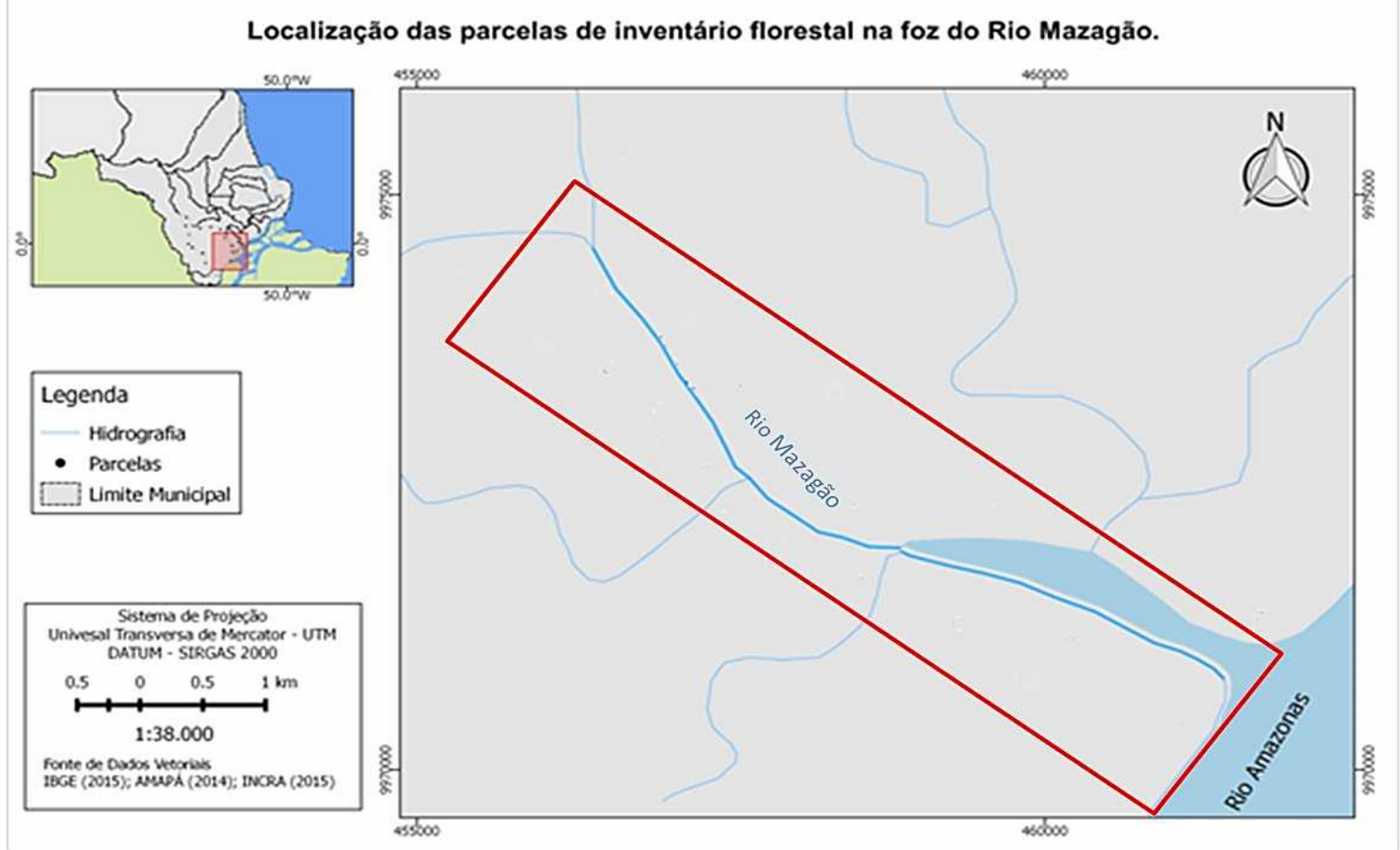

FIGURA 1 - Localização da área de pesquisa, na Foz do Rio Mazagão, Amapá. Fonte: Organizado pelos autores. AMAPÁ (2014), IBGE (2015), INCRA (2015).

\section{COLETA DE DADOS}

Foram inventariadas 19 parcelas temporárias em 12 propriedades, correspondendo a $31 \%$ do total de propriedades contabilizadas na comunidade. As unidades amostrais tiveram dimensões variadas, dependendo do uso da terra, segundo classificação IBGE (2013), sendo sorteadas aleatoriamente no fragmento florestal previamente demarcado com auxílio de GPS, ficando 4 de $50 \times 50 \mathrm{~m}$ em área de extrativismo florestal madeireiro, 8 de $35 \times 35 \mathrm{~m}$ para não madeireiro e 7 medindo $38 \times 38 \mathrm{~m}$ para vegetação original. 
O levantamento florístico foi realizado no período de dezembro a fevereiro de 2017. Dentro das unidades amostrais foram obtidos os dados dendrométricos como a altura total e circunferência, posteriormente convertida para diâmetro. Para cada uso da terra selecionado foi amostrado uma área total de 1 ha, com nível de inclusão de circunferência à altura do peito $(\mathrm{CAP}) \geq 30 \mathrm{~cm}$ (árvores), conforme recomenda Silva et al. (2005) para levantamento em ambientes florestais, representando um esforço.

Em casos de indivíduos com fustes ramificados, mediu-se a circunferência de cada fuste desde que pelo menos um tivesse dentro do nível de inclusão estabelecido para o estudo. A altura de cada um dos indivíduos foi estimada a partir da observação visual (SILVA et al., 2005). Foi realizada coleta de material botânico fértil ou vegetativo para posterior identificação junto ao Herbário do Instituto de Pesquisas Científicas e Tecnológicas do Estado do Amapá.

\section{ANÁLISE DOS DADOS}

A estrutura horizontal foi calculada com base nos seguintes parâmetros fitossociológicos: densidade, frequência, dominância, índice de valor de importância, e índices de diversidade (QUADRO 1), conforme Souza e Soares (2013).

QUADRO 1 - Índices de Dominância de Simpson (C), Diversidade de Simpson (D) e de Shannon (H') e Equabilidade de Pielou (J) em área de várzea da Foz do Rio Mazagão, Amapá.

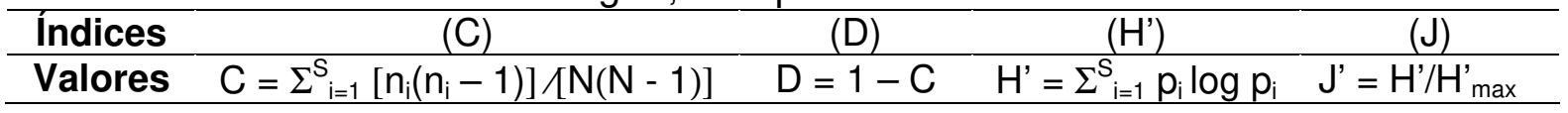

Para estimativa dos parâmetros utilizou-se o Microsoft Office Excel 2010 para organização dos metadados, seguido do carregamento no software Fitopac 2.1 (SHEPHERD, 2007). As figuras foram elaboradas com o software estatístico R ( $R$ Core Team, 2016). Para estudo da distribuição diamétrica, a amplitude e o número de classes a serem utilizados foram calculados conforme a metodologia descrita por Higuchi et al. (2008).

O material botânico fértil ou vegetativo coletado para identificação foi prensado, seco em estufa, herborizado segundo metodologia usual em botânica, baseado no trabalho de (PINHEIRO, 2014). A identificação dos exemplares foi feita com o auxílio de comparações à exsicatas depositadas no Herbário Amapaense (HAMAB), além de consulta à especialistas. Para a apresentação dos táxons foi adotado o sistema Angiosperm Phylogeny Group III (2009) e os nomes científicos das espécies foram confirmados segundo nomenclatura do Missouri Botanical Garden (TROPICOS, 2017).

\section{RESULTADOS E DISCUSSÃO}

\section{SUFICIÊNCIA AMOSTRAL}

$\mathrm{Na}$ Figura 2 a curva do coletor evidenciou que a amostragem foi suficiente para o local estudado, visto que houve tendência à estabilização no surgimento de espécies novas entre as parcelas 18 e 19 (Figura 2). Esta se faz necessária para demonstrar que a área amostrada foi suficiente para o estudo, baseando-se no número de espécies encontradas em função do esforço amostral. 
Curva Espécie X Área

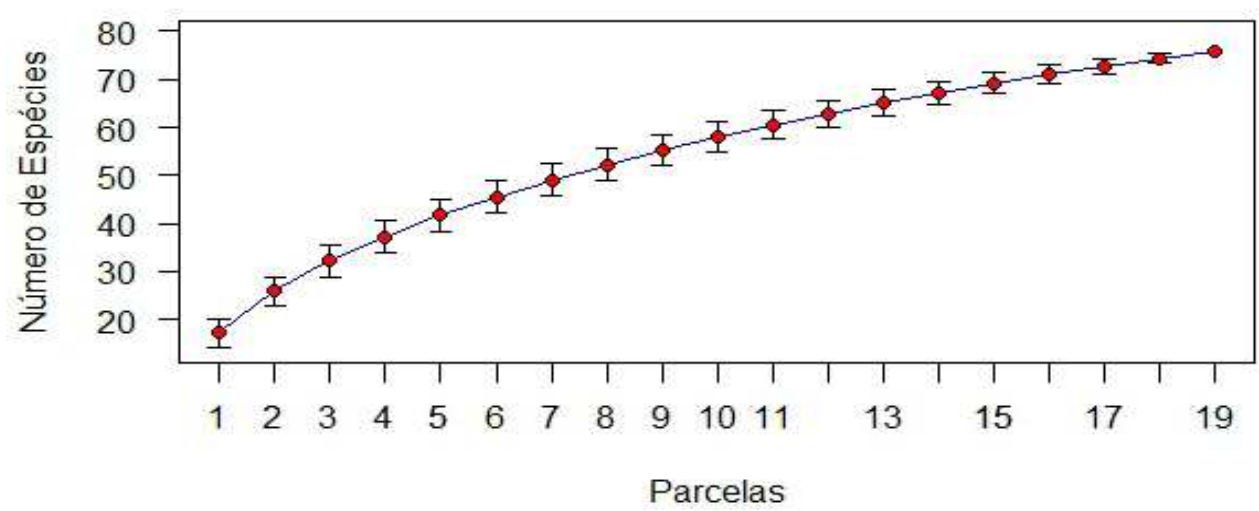

FIGURA 2 - Estimativa da suficiência amostral em estudo realizado na Foz do Rio Mazagão, Amapá.

Fonte: Autores, (2017).

\section{ESTRUTURA DA FLORESTA}

A população estudada apresentou densidade de 78,7 ind. ha ${ }^{-1}$, área basal média de 23,6 $\mathrm{m}^{2}$. ha ${ }^{-1}$, dominância absoluta de número de indivíduos de $7,05 \mathrm{~m}^{2}$. $\mathrm{ha}^{-1}$. Para valores de média de diâmetro, altura e volume, obteve-se 29,3 cm, 20,4 m e 2,3 $\mathrm{m}^{3}$, respectivamente.

A distribuição dos indivíduos por classe de diâmetro gerou 11 classes diamétricas com amplitude de $10,7 \mathrm{~cm}$, de maneira que a primeira classe foi de 9,55 a $20,25 \mathrm{~cm}$ e a última $\geq 127,25 \mathrm{~cm}$, seguindo a distribuição de "J-invertido", que é típica das florestas nativas (LIMA; LEÃO, 2013). O maior número de indivíduos se concentrou nas primeiras classes de diâmetro, com decréscimo do número de indivíduos nas classes de maior DAP, que segue o padrão comum em florestas tropicais (Figura 3).

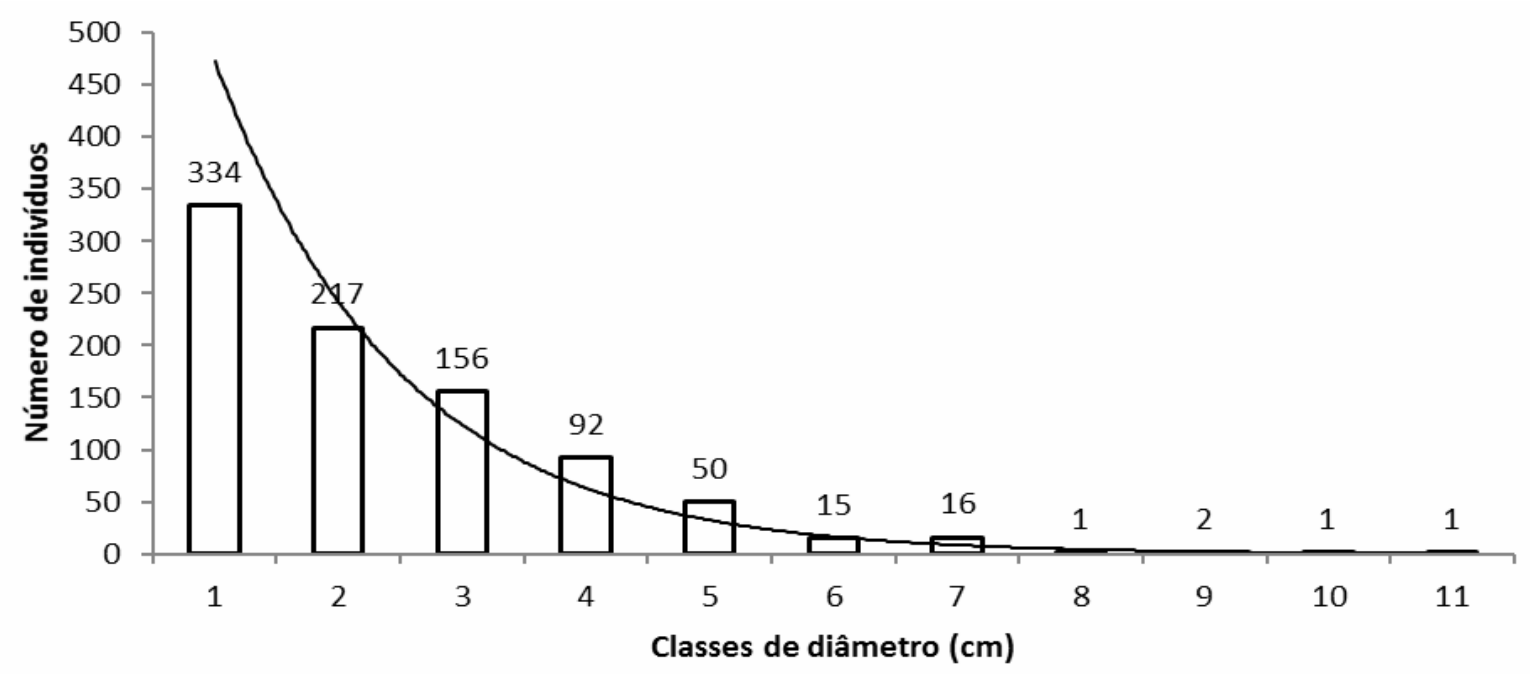

FIGURA 3 - Distribuição diamétrica dos indivíduos arbóreos (DAP $\geq 10 \mathrm{~cm}$ ) inventariados na Foz do Rio Mazagão, Amapá.

Fonte: Autores, (2017).

A estrutura diamétrica da área apresentou $37,7 \%$ dos indivíduos amostrados inseridos na primeira classe diamétrica $(9,55-20,25 \mathrm{~cm})$, o que indica um acentuado ENCICLOPÉDIA BIOSFERA, Centro Científico Conhecer - Goiânia, v.14 n.26; p.599 
número de indivíduos jovens na comunidade estudada. Os resultados assemelhamse aos encontrados por Santos et al. (2013) e Vieira et al. (2015) em estudos realizados em ambientes de várzea no Amapá. Segundo Araújo (2006), essa evidência reflete um estande florestal composto, em sua maioria, por populações jovens em pleno desenvolvimento, que indica que a comunidade estudada tem grande potencial para se regenerar.

Essa distribuição seguiu uma função clássica de distribuição exponencial que segundo a teoria de De Liocourt (1988), trata-se de uma amostra vegetacional com distribuição diamétrica balanceada, conforme tendência natural das florestas tropicais multiâneas. O conhecimento sobre a estrutura diamétrica de uma floresta tem sido uma importante ferramenta na tomada de decisão de áreas com potencial de exploração madeireira de forma sustentável e um elemento importante no auxílio para construção de planos de manejo florestais de impacto reduzido.

\section{ASPECTOS FLORÍSTICOS E FITOSSOCIOLÓGICOS}

O inventário florestal demonstrou que os 885 indivíduos arbóreos amostrados pertencem a 65 espécies, agrupadas em 28 famílias botânicas, sendo Fabaceae (510), Rubiaceae (64), Meliaceae (49), Malvaceae (38), Euphorbiaceae (31), Melastomataceae (25), Lauraceae e Sapotaceae (23), Chrysobalanaceae (22), Myristicaceae (18) as famílias que apresentaram maior abundância de indivíduos, englobando $88,1 \%$ de todos os indivíduos amostrados na área de estudo.

As famílias com maior riqueza de espécies na amostragem total foram: Fabaceae com 17 espécies (26,15\%), Sapotaceae e Malvaceae com quatro espécies cada (6,15\%), Meliaceae, Euphorbiaceae, Moraceae, Clusiaceae, apresentaram 3 espécies cada $(4,62 \%)$, sete famílias apresentaram dois espécies cada $(3,08 \%)$ e outras 14 com um espécie apenas cada (1,54\%). Essas sete famílias concentraram $56,9 \%$ do total de espécies levantadas.

Em ambiente de várzea, Lau e Jardim (2013) registraram 5.731 indivíduos em 2,75 ha, distribuídos em 21 famílias, 51 gêneros, 61 espécies, sendo que a família com maior número de espécies foi a Fabaceae com 14 espécies (22,9\%), que corrobora com o estudo atual, por sua vez, Santos et al. (2016) em ambiente de várzea no estado Amapá, registraram que a família Fabaceae, da mesma maneira, foi uma das que apresentou o maior número de espécies.

Outros estudos também realizados no Amapá demonstraram que a família Fabaceae tem sido constantemente citada como uma das famílias com maior número de espécies (SANTOS et al., 2016; SILVA et al., 2014). A presença das famílias Fabaceae, Lecythidaceae, Sapotaceae e Burseraceae entre as famílias mais abundantes e diversas é um ponto comum entre os levantamentos florestais na região amazônica (QUEIROZ; MACHADO, 2008; SANTOS et al., 2016). Dentre as espécies mais abundantes, a Mora paraensis (Ducke) Ducke (260), Pentaclethra macroloba (Willd.) Kuntze (104), Calycophyllum spruceanum (Benth.) Hook. f. ex K. Schum. (62) contribuíram com 426 indivíduos (Tabela 2), o que corresponde a $48,1 \%$ da densidade total amostrada.

TABELA 2 - Parâmetros fitossociológicos das 20 principais espécies amostradas na Foz do Rio Mazagão, Amapá. Ni: número de indivíduos; DR: densidade 
relativa; DoR: dominância relativa; FR: frequência relativa; IVI: índice de valor de importância.

\begin{tabular}{lccccc}
\hline Espécies & Ni & DR & DoR & FR & IVI \\
\hline Mora paraensis & 260 & 29,38 & 29,96 & 5,9 & 65,24 \\
Pentaclethra macroloba & 104 & 11,75 & 6,34 & 5,9 & 24 \\
Calycophyllum spruceanum & 62 & 7,01 & 12,69 & 4,35 & 24,04 \\
Swartzia cardiosperma & 42 & 4,75 & 3,96 & 5,9 & 14,61 \\
Crudia pubescens & 41 & 4,63 & 1,85 & 4,35 & 10,87 \\
Carapa guianensis & 38 & 4,29 & 3,86 & 4,97 & 13,12 \\
Hevea brasiliensis & 29 & 3,28 & 7,39 & 4,66 & 15,32 \\
Licania heteromorpha & 19 & 2,15 & 5,37 & 3,11 & 10,63 \\
Pterocarpus amazonicus & 21 & 2,37 & 2,83 & 4,06 & 9,24 \\
Matisia paraensis & 25 & 2,82 & 2,52 & 3,73 & 9,07 \\
Virola surinamensis & 18 & 2,03 & 2,28 & 3,73 & 8,04 \\
Mouriri grandiflora & 21 & 2,37 & 0,92 & 3,73 & 7,02 \\
Platymiscium filipes & 13 & 1,47 & 1,87 & 2,48 & 5,82 \\
Licaria mahuba & 18 & 2,03 & 0,93 & 2,8 & 5,76 \\
Pouteria biloculares & 10 & 1,13 & 1,91 & 2,2 & 5,21 \\
Sarcaulus brasiliensis & 9 & 1,02 & 0,59 & 2,48 & 4,09 \\
Quararibea guianensis & 9 & 1,02 & 0,28 & 2,17 & 3,47 \\
Inga sp1 & 8 & 0,9 & 0,21 & 2,17 & 3,29 \\
Trichilia surinamensis & 7 & 0,8 & 0,82 & 1,24 & 2,85 \\
Ormosia coutinhoi & 4 & 0,45 & 1,1 & 1,24 & 2,8 \\
\hline Subtotais & $\mathbf{2}$ & 85,65 & 87,68 & 71,17 & 244,49 \\
Outras & 127 & 14,35 & 12,32 & 28,83 & 55,51 \\
\hline Totais & $\mathbf{1 0 0}$ & $\mathbf{1 0 0}$ & $\mathbf{1 0 0}$ & $\mathbf{3 0 0}$ \\
\hline & & & & & \\
\hline
\end{tabular}

Destaca-se que a espécie $M$. paraensis é comumente relatada como uma das mais abundantes em inventários em florestas de várzea na Amazônia, inclusive no Estado do Amapá (QUEIROZ; MACHADO, 2008; LAU; JARDIM, 2013). Esse fato pode estar relacionado aos mecanismos de adaptação com a diversidade da área, onde as espécies com estratégias mais eficientes são dominantes e mais representativas quantitativamente na comunidade (MAUÉS, 2011).

No que diz respeito ao índice de valor de importância, as três espécies que tiveram destaque foram Mora paraensis, Calycophyllum spruceanum e Pentaclethra macroloba, conforme Tabela 2. Esse parâmetro fitossociológico indica a importância ecológica de uma determinada espécie dentre os indivíduos que compõem uma amostra de população florestal, além de ser um relevante instrumento nos planos de manejo e na categorização ecológica das espécies no povoamento florestal (SOUZA; SOARES, 2013; VIEIRA et al. 2015).

De acordo com Oliveira e Amaral (2004), o valor de importância estimado para as espécies vegetais, em áreas não perturbadas, pode ser utilizado em planos de manejo, como indicador da importância ecológica, devido à influência das 
espécies mais frequentes e dominantes nos processos básicos de equilíbrio da flora e manutenção da fauna, fornecendo abrigo e alimentação.

Quanto às frequências relativas, as espécies de maior destaque foram Mora paraensis, Pentaclethra macroloba, Swartzia cardiosperma, Carapa guianensis, Hevea brasiliensis, Calycophyllum spruceanum, Crudia pubescens, Pterocarpus amazonicus. Por outro lado, as demais espécies apresentaram frequências relativas abaixo de 4\%, resultados que corroboram com o estudo de Lau e Jardim (2013) em floresta de várzea no Estado do Pará.

A baixa frequência observada para várias espécies pode estar relacionada ao modo de dispersão das mesmas ou em decorrência do histórico de exploração pelo qual passou a região da Foz do Rio Mazagão, podendo-se citar a Virola surinamensis, uma das espécies madeireiras mais exploradas na várzea amapaense (MMA, 2014).

\section{Índices de Diversidade}

O H' para a área total foi de 2,959 nats/indivíduo (Tabela 3), indicando que esse ambiente florestal apresenta diversidade florística baixa, pois não suplantou os limites máximos de 4,5 a 5,0 nats/indivíduo para as comunidades naturais (SOUZA; SOARES, 2013). O índice de Shannon é derivado da probabilidade de se obter uma sequência de espécies predeterminadas contendo todas as espécies da amostra.

TABELA 3 - Valores dos índices de Dominância de Simpson (C), Diversidade de Simpson (D) e de Shannon (H') e Equabilidade (J) em área de várzea da Foz do Rio Mazagão, Amapá.

\begin{tabular}{c|c|c|c|c}
\hline Índices & $(\mathrm{C})$ & $(\mathrm{D})$ & $\left(\mathrm{H}^{\prime}\right)$ & $(\mathrm{J})$ \\
\hline Valores & 0,116 & 0,884 & 2,959 & 0,709 \\
\hline
\end{tabular}

Em estudo em floresta de várzea no estuário do Estado do Amapá, Santos et al. (2016) obtiveram índice de 2,84 nats/indivíduo. Enquanto que Almeida e Jardim (2011) encontraram valor de $\mathrm{H}^{\prime}=3,95 \mathrm{em}$ estudo realizado em 2 hectares de floresta de várzea no Pará. Lima et al. (2012) encontraram índice de diversidade de Shannon igual a 3,75 nats/indivíduo. Para Maués (2011), esses valores similares indicam que algumas espécies estão com altas densidades e outras com baixo número de indivíduos no local estudado, inferindo que certas espécies têm maior capacidade de adaptação às condições limitantes do ambiente de várzea.

De acordo com Ferreira et al. (2013), a riqueza e diversidade de espécies nas florestas de várzea na região do estuário amazônico é menor à daquela obtida nas várzeas das regiões geográficas da Amazônia Central e Oriental. Quando comparada a floresta de terra firme, a várzea possui menor diversidade de espécies, no entanto, é a que apresenta a maior diversidade do planeta, dentre todos os ecossistemas inundáveis (WITTMANN et al., 2013), apresentando diversas espécies endêmicas e de elevada importância socioeconômica para os ribeirinhos.

Ainda na Tabela 3 quanto ao índice de equabilidade ( $\mathrm{J}$ '), nota-se que houve uniformidade na amostra com valor de 0,709, indicando que as espécies tendem a distribuírem-se mais uniformemente dentro da comunidade vegetal. Resultado semelhante encontrado por Almeida e Jardim (2011) com J'=0,68, que pode estar associado à forma de dispersão das sementes do grau de adaptabilidade dessas espécies ao regime de inundação que sofre diariamente o ambiente.

O valor de J' obtido para as espécies sugerem que a distribuição dessas plantas dentro da comunidade é moderadamente uniforme. De qualquer forma, o 
grau de J' estimado para a área amostrada indica que a distribuição das espécies dentro daquele ambiente é uniforme, uma vez que o valor aproximou-se de 1 e quanto maior o valor de $\mathrm{J}$, maior será a diversidade florística da comunidade em estudo (SOUZA; SOARES, 2013).

O índice de dominância de Simpson indica que a probabilidade de amostrar aleatoriamente dois indivíduos da mesma espécie é relativamente baixa, apresentando valor de 1,6\%. Tal valor é inversamente proporcional à medida encontrada para a diversidade de Simpson, que indicou uma diversidade relativamente alta com valor de 0,884 .

\section{POTENCIALIDADE E USO DAS ETNOESPÉCIES}

No Quadro 1 são listadas as espécies, o número de indivíduos inventariados e a empregabilidade de utilização no Projeto de Assentamento agroextrativista (PAE) Foz do Mazagão Velho.

QUADRO 1 - Listagem de espécies amostradas, famílias botânicas e usos locais baseados na percepção dos assentados da Foz do Rio Mazagão, Amapá.

Família/Etnoespécie

\section{Anacardiaceae}

Tapereba
Nome Científico

Spondias mombin L.

\section{Empregabilidade}

Alimentação humana e animal, problemas renais, diarréia, gripe, lavagem e cicatrização de ferimentos, inflamação uterina e vaginal, garganta inflamada, tosse, banho de asseio pós parto

\section{Annonaceae}

Envira

Guatteria poeppigiana Mart.

Desnutrição, fraqueza, gripe, cicatrização de feridas, frieira, diarréia, diabetes, cólicas, regular menstruação, garganta inflamada, aftas, tosse, limpeza de ferimentos, asseio vaginal.

\begin{tabular}{ll}
\hline Envireira & Duguetia surinamensis R. E. Fr. \\
Malvaceae & Matisia paraensis Huber \\
\hline Mamoçurana & Pachira aquatica Aubl. \\
\hline Inajarana & Quararibea guianensis Aubl. \\
\hline Cacau & Theobroma cacao L.
\end{tabular}
caixotaria.

Vermífugo, alimentação humana e animal Medicina popular, alimentação humana e animal, biodiesel.

Hematomas, artesanato e construção diversa. Chocolate, geléia, doces, vinagre, álcool, diurética, impotência, alimentação humana e animal.

\begin{tabular}{lll}
\hline Capoteiro & Sterculia speciosa K. Schum & $\begin{array}{l}\text { Construção leve, caixotaria em geral, } \\
\text { assoalhamento e embarcação. }\end{array}$ \\
\hline Samaúmeira & Ceiba pentandra (L.) Gaertn. & $\begin{array}{l}\text { Conjuntivites, diabete, diarréia, disenteria, } \\
\text { gota, inflamação cutânea, picada de inseto, } \\
\text { caixas, brinquedos, barris de pouca duração, } \\
\text { jangadas, palitos, fósforos, construção naval. }\end{array}$ \\
\hline Chapeu de sol & Apeiba burchellii Sprague & $\begin{array}{l}\text { Cólicas, hemorroidas, disenteria, febres } \\
\text { gástricas, febres biliares, vermes intestinais, } \\
\text { emulsões peitorais. }\end{array}$
\end{tabular}

\section{Burseraceae}

Breu

Protium sp1
Construção leve, construção pesada, móveis, marcenaria, caixas, engradados, postes e moirões

Breu branco

Protium pubescens (Benth.)

Engl.
Marcenaria, construção, carpintaria, caixotaria, carvão, medicina popular. 


\section{Celastraceae \\ loioca \\ Chrysobalanaceae \\ Farinha seca}

Macucu

Clusiaceae

Jacareuba
Maytenus sp

Hirtella sprucei Benth. ex

Hook.f.

Licania heteromorpha Benth.
Medicina popular.

Estacas, cabo de enxada, barrote, carvão, lenha.

Atividade medicinal, construção naval, construção civil, artesanato.

Calophyllum brasiliense

Cambess.

Marcenaria, carpintaria, construção civil e naval, ripados, compensado, cabos de instrumentos, cutelaria, soalhos e persianas, diabetes, hipertensão, doenças gastrointestinais, respiratórias e inflamatórias.

$\begin{array}{lll}\text { Anani Symphonia globulifera L.f. } & \begin{array}{l}\text { Erisipela, tirar frieza do corpo, rasgadura, } \\ \text { ferimentos crônicos, hematomas, problemas do }\end{array}\end{array}$
pulmão e cicatrizante.

Bacuri Rheedia acuminata (Ruiz \& Aparelho urinário, artritismo, inflamação,
Pav.) Planch. \& Triana reumatismo, nevralgia, úlcera gástrica, construção madeireira de pequeno porte.

\section{Euphorbiaceae}

Seringueira

Hevea brasiliensis (Willd. ex A.Juss.) Müll.Arg.

Curupita Sapium curupita Huber

Açacu Hura crepitans L.

Fabaceae

\begin{tabular}{ll}
\hline Iperana & Crudia pubescens Benth. \\
\hline Mututi & Pterocarpus amazonicus Huber
\end{tabular}

Pacapeua Swartzia polyphylla DC.

Pracuúba

Mora paraensis (Ducke) Ducke

$\begin{array}{ll}\text { Pracaxi } & \begin{array}{l}\text { Pentaclethra macroloba (Willd.) } \\ \text { Kuntze }\end{array}\end{array}$

Ingá de sapo Inga sp1

Macacaúba

Platymiscium filipes Benth.

Faveira

Vatairea guianensis Aubl.

\begin{tabular}{l} 
Pitaíca \\
\hline Ingarana
\end{tabular}

Buiuçu

Swartzia racemosa Benth.

Zygia latifolia (L.) Fawc. \& Rendle

Ormosia coutinhoi Ducke

Ingá

Jutaí folha fina
Inga edulis Mart. Alimentação,

Alimentação, Infecção do intestino, hemorroida, Aftas, combustível e comercial.

Hymenaea oblongifolia Huber Construção em geral, dormentes, torneados, popular,

Furúnculo, lepra, reumatismo, caixas,
tamancos, artefatos de madeira, forros, compensados.

Utensílios na propriedade. saf, brinquedos e combustível.

Medicina popular e científica, alimentação humana e animal, combustível e recuperação de área.

Marcenaria, dormentes esteios, assoalhos, vigamento, carpintaria, moirões estacas, construção civil, construção naval e alimentação animal.

Dor de cabeça, gastrite, inflamação, pneumonia, veneno de cobra, cicatrizante, inchaço e combustível.

Dor, reumatismo, problemas intestinais, diarreia, disenteria, dor de cabeça, alimentício, lenha, caixotaria, ornamental.

Marcenaria, compensado, carpintaria, construção civil, assoalhos, moveis e instrumentos musicais.

Construção leve, estruturas leves, divisórias, paredes, esquadrias e artesanato.

Medicinal, artesanato e combustível.

Construção em geral, faqueados decorativos e combustível.

Construção leve, estruturas, assoalhos divisórias, paredes esquadrias, moveis, caixas chapas, marcenaria, embarcações e artigos
Construção diversa, borracha, medicina 


\begin{tabular}{|c|c|c|}
\hline & & decorativos. \\
\hline Mututirana & Pterocarpus officinalis Jacq. & $\begin{array}{l}\text { Artesanato, construção diversa, composição de } \\
\text { saf, brinquedos e combustível. }\end{array}$ \\
\hline Acapurana & Campsiandra laurifolia Benth. & $\begin{array}{llll}\begin{array}{l}\text { Artesanato, } \\
\text { comercial. }\end{array} & \text { combustível, } & \text { construção } & \text { e } \\
\end{array}$ \\
\hline Pau ferro & Apuleia ferrea (Mart.) Baill. & $\begin{array}{l}\text { Construção civil e naval, mobiliário fino, } \\
\text { carvão, alimentação animal, medicina popular, } \\
\text { produção melífera, arborização urbana, } \\
\text { paisagismo. }\end{array}$ \\
\hline \multicolumn{3}{|c|}{ Hernandiaceae } \\
\hline \multirow{2}{*}{\multicolumn{3}{|c|}{ Humiriaceae }} \\
\hline & & \\
\hline Uxirana & Sacoglottis guianensis Aubl. & $\begin{array}{l}\text { Construção civil, móveis e carpintaria, } \\
\text { recuperação de áreas degradadas, artesanato, } \\
\text { alimentação humana, alimentação animal e } \\
\text { medicinal/Fármaco. }\end{array}$ \\
\hline \multicolumn{3}{|l|}{ Lauraceae } \\
\hline Maúba & $\begin{array}{l}\text { Licaria mahuba (A. Samp.) } \\
\text { Kosterm. }\end{array}$ & Construção naval e construção civil. \\
\hline Louro & Nectandra amazonum Ness & $\begin{array}{l}\text { Dor de cabeça, espasmos, reumatismo, } \\
\text { estômago, fígado, gases, construções civil e } \\
\text { naval, compensados. }\end{array}$ \\
\hline
\end{tabular}

Jenipapana $\quad$ Gustavia augusta L. $\quad$ As raízes são usadas como laxantes, suas folhas como descongestionantes e contra a icterícia. A casca serve para o curtimento e couros. Muito utilizada como ornamental em projetos paisagísticos. Alimentação.

Sapucaia Lecythis pisonis Cambess. Alimentação, problemas de pele (micose), coceira, catapora, sarampo, hepatite, anemia, diarréia, Sífilis, diurética, infecções, problemas das vias urinárias, medicina caseira, artesanato e construção.

Melastomataeae

Camutim Mouriri grandiflora DC.

Jacamim Mouriri princeps Naudin

Meliaceae

Andiroba Carapa guianensisAubl.
Alimentação humana e animal, construção em geral, medicina popular.

Alimentação humana e animal, construção em geral, medicina popular.

Reumatismo, vermes, inflamações da pele, cicatrizante, anti-inflamatório, inflamação da garganta, repelentes de insetos, micoses, construção civil e naval e compensados.

\begin{tabular}{lll}
\hline Jataúba & Trichilia paraensis C. DC. & $\begin{array}{l}\text { Marcenaria, carpintaria, construção em geral } \\
\text { artesanato. }\end{array}$ \\
\hline Marajoão & $\begin{array}{l}\text { Trichilia surinamensis (Miq.) C. } \\
\text { DC. }\end{array}$ & Alimentação animal, lenha. \\
Urticaceae &
\end{tabular}

Embauba Cecropia leucocoma Miquel Reumatismo, pedra na vesícula, desidratação, anemia, infecção urinária, inchaço, malária, hepatite, asma, bronquite, gonorreia.

\begin{tabular}{ll}
$\begin{array}{l}\text { Moraceae } \\
\text { Apuí }\end{array}$ & Ficus numphaeifolia L. \\
\hline Muiratinga & $\begin{array}{l}\text { Naucleopsis caloneura (Huber) } \\
\text { Ducke }\end{array}$ \\
$\begin{array}{l}\text { Myristicaceae } \\
\text { Virola }\end{array}$ & $\begin{array}{l}\text { Virola surinamensis (Rol. ex } \\
\text { Rottb.) Warb. }\end{array}$
\end{tabular}

Paisagismo, sombreamento e cerca viva, medicinal Marcenaria, construção naval e construção em geral.

Compensado, combustível, caixotaria, construções internas, marcenaria, estacas, palitos, artesanato, urnas funerárias, alimento 
para a fauna, cólicas do intestino, ferimentos, cicatrizar feridas, inflamação do útero.

\begin{tabular}{|c|c|c|}
\hline \multicolumn{3}{|l|}{ Putranjivaceae } \\
\hline Maparanã & Drypetes variabilis Uittien & $\begin{array}{l}\text { Medicina popular, construção em geral, postes, } \\
\text { moirões. }\end{array}$ \\
\hline \multicolumn{3}{|l|}{ Rubiaceae } \\
\hline Pau mulato & $\begin{array}{l}\text { Calycophyllum spruceanum } \\
\text { (Benth.) Hook.f. ex K. Schum. }\end{array}$ & $\begin{array}{l}\text { Cicatrizante, repelente, inseticida, combustível, } \\
\text { caixotaria, construções internas, marcenaria, } \\
\text { estacas, artesanato. }\end{array}$ \\
\hline Canela de velha & $\begin{array}{l}\text { Chimarrhis barbata (Ducke) } \\
\text { Bremek. }\end{array}$ & Recuperação de área, utensílios domésticos. \\
\hline \multicolumn{3}{|l|}{ Salicaceae } \\
\hline Andorinha & Banara guianensis Aubl. & $\begin{array}{l}\text { Medicina popular, combustível, pequenas } \\
\text { construções e melífera, atividade inseticida. }\end{array}$ \\
\hline \multicolumn{3}{|l|}{ Sapotaceae } \\
\hline Jaraí & $\begin{array}{l}\text { Sarcaulus brasiliensis (A. DC.) } \\
\text { Eyma }\end{array}$ & $\begin{array}{l}\text { Alimentação humana e animal, arborização } \\
\text { urbana, carpintaria em geral, tornearia, cabos } \\
\text { de ferramentas, construção de casas e de } \\
\text { embarcações. }\end{array}$ \\
\hline Guajará & $\begin{array}{l}\text { Chrysophyllum venezuelanense } \\
\text { (Pierre) T.D.Penn. }\end{array}$ & $\begin{array}{l}\text { Alimentação humana e animal, ornamental e } \\
\text { boa sombra, paisagismo, carpintaria. }\end{array}$ \\
\hline Abiurana & $\begin{array}{l}\text { Pouteria bilocularis } \\
\text { (H.J.P.Winkl.) Baehni }\end{array}$ & $\begin{array}{l}\text { Serraria, construção em geral, alimentação } \\
\text { animal, medicina popular, combustível. }\end{array}$ \\
\hline Maçaranduba várzea & $\begin{array}{l}\text { Pouteria sagotiana (Baill.) } \\
\text { Eyma }\end{array}$ & Marcenaria, carpintaria, construção em geral. \\
\hline \multicolumn{3}{|l|}{ Siparunaceae } \\
\hline Capitiú & Siparuna guianensis Aubl. & $\begin{array}{l}\text { Medicina popular, febres, pressão arterial alta, } \\
\text { para doenças reumáticas e também contra } \\
\text { cólicas, anti-inflamatório. }\end{array}$ \\
\hline
\end{tabular}

Além de possuir uma grande riqueza biológica formada pelos ambientes naturais, a floresta amazônica possui uma grande riqueza cultural proveniente do conhecimento das populações locais. O uso de etnoespécies pela população mundial tem sido muito significativo nos últimos anos (RIBEIRO et al., 2017). O etnoconhecimento dos povos que habitam as florestas pode servir para indicar novos usos de espécies existentes e usos para espécies previamente desconhecidas (OLIVEIRA et al., 2015).

\section{CONCLUSÕES}

A estrutura florestal da Foz do Rio Mazagão apresenta boa capacidade de regeneração. As famílias Fabaceae, Rubiaceae, Meliaceae, Malvaceae, Euphorbiaceae, Melastomataceae, Lauraceae, Sapotaceae, Chrysobalanaceae, Myristicaceae apresentaram maior abundâcia de indivíduos. As espécies mais abundantes foram Mora paraensis, Pentaclethra macroloba e Calycophyllum spruceanum.

A população local mantém estreita ligação com as etnoespécies que ocorrem na comunidade. É amplo o conhecimento dos assentados a respeito das plantas. Todas as etnoespécies identificadas apresentaram diversas empregabilidades pela população local, especialmente no que diz respeito à alimentação humana, na medicina popular por meio da prevenção e/ou curas de doenças, manutenção da fauna e uso diversificado na propriedade.

\section{REFERÊNCIAS}


ALMEIDA, A. F.; JARDIM, M. A. G. Florística e estrutura da comunidade arbórea de uma floresta de várzea na llha de Sororoca, Ananindeua, Pará, Brasil. Scientia Forestalis, Piracicaba, v.39, n.90, p.191-198, 2011. Disponível em:< http://www.ipef. br/publicacoes/scientia/nr90/cap07.pdf.>.

ALMEIDA, L. S.; GAMA, J. R.; OLIVEIRA, F. A.; CARVALHO, J. O.; GONÇALVES, D. C.; ARAÚJO, G. C. Fitossociologia e uso múltiplo de espécies arbóreas em floresta manejada, Comunidade Santo Antônio, município de Santarém, Estado do Pará. Acta Amazônica. v. 42, n.2, p. 185 - 194, 2012. Disponível em:<http://dx.doi.org/10.1590/S0044-59672012000200002>. DOI: 10.1590/S0044-59 672012000200002

APG III. Angiosperm Phylogeny Group classification for the orders and families of flowering plants: APG III. Botanical Journal of the Linnean Society, v. 161, n. 2, p. 105-121, 2009.

ARAUJO, H. J. B. Inventário florestal a $100 \%$ em pequenas áreas sob manejo florestal madeireiro. Revista Acta Amazônica. v. 36(4), p. 447 - 464, Amazonas, 2006. Disponível em:<http://www.scielo.br/pdf/aa/v36n4/v36n4a07>.

BRASIL, Ministério do Meio Ambiente. Portaria MMA № 443, De 17 de Dezembro de2014. Disponível_em:<http://cncflora.jbrj.gov.br/portal/static/pdf/portaria_mma_ 443_2014.pdf>. Acessado em: 15 de Janeiro de 2017.

CHAVES, A. D.; SANTOS, R. M.; SANTOS, J. O.; FERNANDES, A. A.; MARACAJÁ, P. B. A importância dos levantamentos florístico e fitossociológico para a conservação e preservação das florestas. ACSA - Agropecuária Científica no Semiárido, v. 9, n. 2, p. 43-48, Paraíba, 2013. Disponível em:< http://revistas.ufcg. edu.br/acsa/index.php/ACSA/article/download/449/pdf>.

DE LIOCOURT, F. De l'amenagement des sapinières. Bulletin trimestriel, Société forestière de Franche-Comté et Belfort, Franche. p. 396-409. 1998.

FERREIRA, L. V.; CHAVES, P. P.; CUNHA, D. A.; MATOS, D. C. L.; PAROLIN, P. Variação da riqueza e composição de espécies da comunidade de plantas entre as florestas de igapós e várzeas na estação científica Ferreira Penna-Caxiuanã na Amazônia oriental. Pesquisas, Botânica, no 64, 175-195, 2013. Disponível em:

$<$ http://www.anchietano.unisinos.br/publicacoes/botanica/botanica64/11_ferreira\%20 e\%20parolin.pdf.>.

HIGUCHI, N.; SANTOS, J.; LIMA, A. J. N. Biometria florestal. Instituto nacional de pesquisas da Amazônia. Coordenação de pesquisas em silvicultura tropical laboratório de manejo florestal - Imf. Manaus-AM. 2008.

IBGE. Instituto Brasileiro de Geografia e Estatística, 2013. Manual Técnico do uso da terra. Manuais Técnicos em Geociências. Número 7. 2013. Disponível em: < https://biblioteca.ibge.gov.br/visualizacao/livros/liv81615.pdf>. 
LAU, A. V.; JARDIM, M. A. G. Florística e estrutura da comunidade arbórea em uma floresta de várzea na Área de Proteção Ambiental, Ilha do Combu, Belém, Pará. Biota Amazônia, Macapá, v. 3, n. 2, p. 88-93, 2013. Disponível em: <http://dx.doi. org/>. DOI: 10.18561/2179-5746/biotaamazonia.v3n2p88-93

LIMA, R. B. A.; SILVA, J. A. A.; MARANGON, L. C.; FERREIRA, R. L. C.; SILVA, R. K. S. Fitossociologia de um trecho de floresta ombrófila densa na Reserva de Desen volvimento Sustentável Uacari, Carauari, Amazonas. Scientia Plena, v. 8, n. 1, 2012. Disponível em: < http://observatorio.wwf.org.br/site_media/upload/gestao/ documentos/npsA1E0.tmp.pdf>.

LIMA, J. P.; LEÃO, J. R. Dinâmica de Crescimento e Distribuição Diamétrica de Fragmentos de Florestas Nativa e Plantada na Amazônia Sul Ocidental. Floresta e Ambiente - Floram. v. 20, n. 1, p. 70-79, 2013. Disponível em: <http://dx.doi.org/.> DOI: 10.4322/floram.2012.065

LOMBA, R. M.; FONSECA, M. B. S. Modos de vida ribeirinho na comunidade Foz do Rio Mazagão - Mazagão (AP/Brasil). Ateliê Geográfico. v. 11, n. 1, Goiânia-GO, p.257-276, 2017. Disponível em:<https://doi.org/10.5216/ag.v11i1.35381>. DOl:10. 5216/ag.v11i1.35381

MAUÉS, B. A. R.; JARDIM, M. A. G.; BATISTA, F. J.; MEDEIROS, T. D.; QUARESMA, A. C. Composição florística e estrutura do estrato inferior da Floresta de várzea na área de proteção ambiental Ilha do Combu, município de Belém, estado do Pará. Revista Árvore, Viçosa-MG, v.35, n.3, Edição Especial, p.669-677, 2011. Disponível em:<http://dx.doi.org/10.1590/S0100-676220110004000 11 >. DOI: 10.1590/S0100-67622011000400011

MISSOURI BOTANICAL GARDEN. Tropicos. 2017. Disponível em: <http://www.tropicos.org. Acesso em: 13 /fev./ 2017>.

OLIVEIRA, A. N.; AMARAL, I. L. Florística de uma floresta de vertente na Amazônia Central, Amazonas, Brasil. Acta Amazônica. v. 34, n. 1, p. 21-34, 2004. Disponível em: <https://acta.inpa.gov.br/fasciculos/34-1/PDF/v34n1a04.pdf.>.

OLIVEIRA, D. R.; KRETTLI, A. U.; AGUIAR, A. C. C.; LEITÃO, G. G.; VIEIRA, M. N.; MARTINS, K. S.; LEITÃO, S. G. Ethnopharmacological evaluation of medicinal plants used against malaria by quilombola communities from Oriximiná, Brazil. Journal of Ethnopharmacology, v. 173, p. 424-434, 2015. Disponível em: < https://doi.org/10. 1016/j.jep.2015.07.035>. DOI: 10.1016/j.jep.2015.07.035

PINHEIRO, A. L. Fundamentos em taxonomia aplicados no desenvolvimento da dendrologia tropical. Editora UFV, Viçosa-MG, 278p. 2014.

QUEIROZ, J. A. L.; MACHADO, S. A. Fitossociologia em floresta de várzea do estuário amazônico no Estado do Amapá. Pesquisa Florestal Brasileira, Colombo, n. 57, p. 05-20, 2008. Disponível em:< https://www.embrapa.br/busca-de-publicaco es/-/publicacao/353283/fitossociologia-em-floresta-de-varzea-do-estuario-amazoni co-no-estado-do-amapa>. 
R Core Team. R: a language and environment for statistical computinging. $\mathrm{R}$ Foundation for Statistical Computing, Vienna, Austria. 2016.<http://www.Rproject.org/>.

RÊGO, L. J. S.; SILVA, M. L.; SILVA, L. F.; GAMA, J. R. V.; L. P. REIS. Comercialização da amêndoa de cumarunos municípios de Santarém e Alenquer, leste da Amazônia. Revista de Administração e Negócios da Amazônia. v. 8, n. 3, set/dez. 2016. Disponível em:<http://www.periodicos.unir.br/index.php/rara/article/ download/1699/1705>. DOI 10.18361/2176-8366/rara.v8n3p338-361

RIBEIRO, R. V. R.; BIESKI, I. G. C.; BALOGUN, S. O.; MARTINS, D. T. O. Ethnobotanical study of medicinal plants used by Ribeirinhos in the North Araguaia microregion, Mato Grosso, Brazil. Journal of Ethnopharmacology, v. 205, p. 69102, 2017. Disponível em: <https://doi.org/10.1016/j.jep.2017.04.023>. DOI: 10.1016/j.jep.2017.04.023

SANTOS, E. S.; APARÍCIO, P. S.; SILVA, T. L.; FREITAS, J. L. Estrutura da espécie Virola surinamensis (Rol.) Ward na floresta estadual do Amapá- FLOTA/AP. Revista de Biologia e Ciencência da Terra. v. 13, n. 1, p. 48 - 61. 2013. Disponível em:<http://joaootavio.com.br/bioterra/workspace/uploads/artigos/657-2767-1-pb53df8e4e4c384.pdf.>.

SANTOS, R. O.; SOARES, R. N.; DANTAS, B. S.; ABREU, J. C.; LIMA, R. B. Processos amostrais para estimativa de parâmetros estruturais de uma floresta estuáriana no estado do Amapá. Nativa: Pesquisas Agrárias e Ambientais, v. 4, n. 5, p.308-316, Sinop, 2016. Disponível: <http://www.periodicoscientificos.ufmt.br/ojs/ index.php/nativa/article/view/3431 >. DOI: 10.14583/2318-7670.v04n05a07

SHEPHERD, G. J. Fitopac 2.1. Manual do usuário. Departamento de Botânica, Universidade Estadual de Campinas. São Paulo, 2007. 93 p.

SILVA, J. N.; LOPES, J. C.; OLIVEIRA, L. C.; SILVA, S. M.; CARVALHO, J. O.; et al. Diretrizes para instalação e medição de parcelas permanentes em florestas naturais da Amazônia Brasileira. Belém, PA: Embrapa Amazônia Oriental, 2005. $68 p$.

SILVA, W. A. S.; CARIM, M. J. V.; GUIMARÃES, J. R. S.; CÁSSIA, L.; TOSTES, L. Composição e diversidade florística em um trecho de floresta de terra firme no sudoeste do Estado do Amapá, Amazônia Oriental, Brasil. Biota Amazônia, Macapá, v. 4, n. 3, p. 31-36, 2014. Disponível em: <http://dx.doi.org/10.18561/21795746/biotaamazonia.v4n3p31-36>.DOI: 10.18561/2179-5746/biotaamazonia.v4n3 p31-36

SOUZA, A. L.; SOARES, C. P. B. Florestas Nativas: estrutura, dinâmica e manejo. Editora UFV, 2013. 322 p.

VERÍSSIMO, A.; PEREIRA, D. Produção na Amazônia Florestal: características, desafios e oportunidades. Parcerias Estratégicas. v. 19, n. 38, Brasília-DF, p. 1344, 2014. Disponível em: http://seer.cgee.org.br/index.php/parcerias_estrategicas/ article/viewFile/731/671 
VIEIRA, D. S.; GAMA, J. R. V.; OLIVEIRA, M. L. R.; RIBEIRO, R. B. S. Análise estrutural e uso múltiplo de espécies arbóreas em florestas manejadas no médio vale do rio Curuá-Una, Pará. Revista Floresta, Curitiba, v. 45, n. 3, p. 465 - 476. 2015. Disponível em: <http://dx.doi.org/> DOI:10.5380/rf.v45i3.35584

WITTMANN, F. ; Habitat specifity, endemism and the neotropical distribution of Amazonian white-water floodplain trees, Ecography, v. 36, p. 690-707, 2013. Dispo nível em: < https://www.researchgate.net/publication/236871880_Habitat_specifity endemism_and_the_Neotropical_distribution_of_Amazonian_white-water_floodplain trees>. DOI: $10.1111 / \mathrm{j} .1600-0587.2012 .07723 . x$

YOKOMIZO, G. K.; MOCHIUTTI, S.; QUEIROZ, J. A. L. SANTOS, G. R.; FURTADO, R. G.; BRANDÃO, A. P.; COLARES, I. B. ESTIMATIVAS de parâmetros genéticos para caracteres de frutos em açaizeiros no Amapá. Ciência Florestal, v. 26, n. 3, p. 985-993, Santa Maria, 2016. Disponível:<https://periodicos.ufsm.br/cienciaflorestal /article/view/24227>. DOI: 10.5902/1980509824227 